\title{
A INCRIVEL HISTÓRIA DA FUNDAÇÃO DA UNIVERSIDADE DO PARANÁ
}

\author{
José Henrique do Carmo ${ }^{1}$
}

- Enviado em 08/08/2015

- Aprovado em 17/08/2015

A mais antiga universidade brasileira, cuja gênese se deveu a um grupo de ousados e corajosos intelectuais paranaenses, cumpriu o seu primeiro centenário no dia 19 de dezembro de 2012.

A sua fundação resgatou o sonho de José Francisco da Rocha Pombo, ilustre cidadão de Morretes, jornalista e notável historiador paranaense, que se propôs, em 1892, fundar uma universidade, a Universidade do Paraná.

As gestões de Rocha Pombo conduziriam o Congresso do Estado à edição da Lei $\mathrm{n}^{\circ} 68$ de 10 de Dezembro de 1892, que lhe outorgava a concessão por 50 anos da Universidade do Paraná concedendo vantagens fiscais, remuneração ao capital investido, direitos de desapropriação e indenização ao final do prazo de concessão.

A Prefeitura de Curitiba cederia terreno no Largo Ouvidor Pardinho para a construção do edifício. Em 22 de Maio de 1893, o vice-governador do Estado convocaria o concessionário para o lançamento da pedra fundamental da Universidade do Paraná que se realizaria no dia seguinte.

\footnotetext{
${ }^{1}$ José Henrique do Carmo, economista pela Universidade Federal do Paraná -UFPR, especialista em Comercialização Interna e Externa pela Organização dos Estados Americanos e Fundação Getúlio Vargas, Rio de Janeiro, mestre em Desenvolvimento Econômico pela UFPR. Foi professor da Universidade Federal do Paraná (1970/1998), foi Pró-Reitor de Planejamento da instituição. Endereço eletrônico: hcarmo@ superig.com.br.
} 
No entanto, apesar das facilidades outorgadas pelo poder público, Rocha Pombo enfrenta limitações financeiras para a realização de seu intento. Desta forma, solicita, em 1893, apoio de nosso Senador Ubaldino do Amaral, que não consegue obter subvenção federal. Em 1894, tenta alteração da lei de concessão para obter subvenção similar a que era despendida para a manutenção Gymnasio Paranaense, não conseguindo. Volta à carga, em 1896, pedindo ao Congresso do Estado prorrogação por cinco anos do prazo para início das atividades e subvenção de sessenta contos de réis e outras vantagens, não obtém sucesso. Morre a tentativa, mas o sonho permanece no ar.

Sonho que é captado simultaneamente, em 1912, em circunstâncias diversas, pelos Médicos Victor Ferreira do Amaral e Silva e Nilo Cairo da Silva, sob a égide da lei federal Rivadávia Corrêa, liberalizante do ensino, editada em 1911.

Victor do Amaral convocaria, no dia 12 de junho de 1912, no escritório do Sr. Miranda Rosa, diretor do Banco de Curityba, um pequeno grupo de cidadãos para tratar da fundação de uma Universidade, conforme reporta o Relatório Geral da Universidade do Paraná, de 1913. Na ocasião é ele designado, juntamente com Pamphilo de Assumpção, para elaborar as bases de um projeto que seria apresentado a uma assembléia mais numerosa de intelectuais paranaenses.

Em fins de julho, parte Victor do Amaral para São Paulo e Rio de Janeiro para estudar a organização das escolas superiores existentes. Em sua volta entrega a Pamphilo de Assumpção a documentação levantada para a elaboração do projeto definitivo. Pamphilo devido aos seus afazeres demora-se em dar cabo da tarefa.

Anteriormente, no mesmo dia em que o jornal Diário da Tarde noticiava a intenção de Victor do Amaral de fundar uma Universidade, e sem ter conhecimento da notícia, Nilo Cairo se reuniria em seu gabinete com o Engenheiro Militar Manoel de Cerqueira Daltro Filho, propondo-se criar um estabelecimento de ensino superior em Curitiba com vários cursos. No dia subseqüente, tomam conhecimento das intenções de Victor do Amaral e Pamphilo de Assumpção, fato que os levou a afastar temporariamente a idéia.

Em fins de outubro de 1912, Nilo Cairo encontrou o Dr. Flavio Ferreira da Luz, diretor do Gymnasio Curytibano, que o convidou para organizar um curso particular de Odontologia que planejava fundar no referido ginásio. Em novo contato, reuniram-se na residência de Nilo, juntamente com Julio Theodorico Guimarães, que tinha a intenção de inaugurar um curso de Comércio, na oportunidade, estabeleceram o projeto de criação dos cursos de Odontologia e 
Comércio. Em função dos obstáculos para associarem-se ao Gymnasio Curytibano, optam por organizar uma associação civil.

Para a organização da futura Escola de Odontologia e de Commercio, escreve Nilo Cairo a entidades similares solicitando estatutos, regulamentos e programas.

Por sugestão do engenheiro Daltro Filho mais um curso é acrescido à escola pretendida, o curso de Agrimensura. A futura escola passou a denominar-se Escola de Agrimensura, Odontologia e Commercio.

Para lente de uma das cadeiras do pretendido curso de Odontologia é convidado, por Nilo, o médico Dr. Reinaldo Machado. O Dr. Machado sugere a criação de um curso de Obstetrícia, argumentando as precárias condições de atendimento das parturientes, a maioria das vezes atendidas por parteiras práticas e desconhecedoras das práticas de higiene, Nilo acede. Para lente do curso é convidado o obstetra Victor do Amaral, que há dois meses havia retornado de sua viagem de pesquisa.

Ao se acrescer mais um curso o nome da futura escola estava longo demais, como batizála? Chegou-se até a aventar a idéia de denominar a escola, Universidade do Paraná, o título era assustador, resolveram adiar a discussão, mas a idéia estava latente.

Todas as noites o número 32 da Praça Tiradentes, onde se situava o gabinete do Médico Homeopata Nilo Cairo, estava iluminado, ao lado de Daltro Filho e Flávio Luz os trabalhos continuavam. Theodorico Guimarães, não tendo disponibilidade de tempo, não participaria das reuniões.

Na primeira quinzena de novembro, mais um curso seria acrescido à escola pretendida, o de Direito, fruto da entusiástica resposta do advogado Hugo Gutierrez Simas, em fortuito encontro na Rua XV de Novembro, à pergunta, de chofre, de Nilo Cairo sobre a idéia de fundar o curso. No mesmo dia, com as informações de estatutos de cursos de Direito obtidas na biblioteca de Hugo Simas e lista de advogados, fornecidas pelo Dr. Vieira de Alencar, Nilo organiza o curso distribuindo as disciplinas pelos nomes indicados.

Reunidos, à noite, Flavio Luz, Daltro Filho, Hugo Simas e Nilo Cairo, definem, audaciosamente, criar a Universidade do Paraná, incluindo nela todos os cursos de uma verdadeira universidade. 
Em poucos dias o grupo convida e organiza o corpo docente dos cursos que pretendiam abrir em março de 1913, que eram: Sciencias Juridicas e Sociais, Agrimensura, Odontologia, Obstetricia e Commercio.

Em 28 de novembro de 1912, Victor do Amaral, que, como visto, já fora convidado para a cadeira de Obstetrícia, aceita o convite para presidir a comissão organizadora da Universidade, e no mesmo dia, o Desembargador Euclides Bevilaqua passa a compor a equipe.

Diria Victor do Amaral, a respeito do convite, no primeiro relatório da Universidade anteriormente aludido: "Vendo que o trabalho de organização do Dr. Nilo Cairo, estava mais adiantado que o meu, e não estando eu agindo por sentimentos subalternos de primazia, acedi de bom grado ao convite que me era feito, certo que assim atingiria mais facilmente ao fim por mim colimado - a fundação da Universidade do Paraná”.(RELATORIO GERAL DA UNIVERSIDADE DO PARANÁ, 1913, p.4).

Nesse período, Nilo Cairo seria convencido pelo Dr. João David Pernetta, em encontro na rua $\mathrm{XV}$, a substituir o curso de Agrimensura pelo de Engenharia. Com o apoio de seu ilustre amigo, Nilo consegue organizar um plano para o Curso de Engenharia, que é aprovado pela comissão.

Os estatutos da Universidade, organizados, passam a contemplar todos os cursos completos, como os cursos de Farmácia, que se viabilizaria já em 1913, o de Medicina no inicio de 1914, Agronomia em 1915 e o de Veterinária, bem mais tarde, em 1931.

Em 11 de dezembro de 1912, Nilo Cairo comunica ao Presidente do Estado Carlos Cavalcanti de Albuquerque a decisão de criar a Universidade, o dirigente estadual, entusiasmado, sugere a data de 19 de dezembro, data comemorativa da emancipação política do Estado, para a sessão inaugural da Universidade, cedendo-lhe o salão das sessões do Congresso Legislativo do Estado. Edifício que hoje abriga a Câmara Municipal de Curitiba.

A sessão da Assembléia Geral para a aprovação dos estatutos e demais propostas seria convocada para as 14 horas do dia 19 de dezembro de 1912 no Congresso Legislativo do Estado, ocasião que foi indicada a estrutura diretiva da Universidade do Paraná composta de uma Diretoria, um Conselho Econômico e um Conselho Superior.

Após discussão, foi aprovada a estrutura diretiva da Universidade que ficou assim composta: 


\section{DIRETORIA}

Diretor, Dr. Victor do Amaral e Silva

Vice-Diretor, Dr. Euclides Bevilaqua

Secretário, Dr. Nilo Cairo da Silva

Subsecretário, Dr. Manoel Cerqueira Daltro Filho

Tesoureiro, Dr. Flavio Ferreira da Luz

Bibliotecário, Dr. Hugo Gutierrez Simas

\section{CONSELHO ECONÔMICO}

Dr. Pamphilo de Assumpção

Dr. Reinaldo Machado

Dr. Arthur Martins Franco

\section{CONSELHO SUPERIOR}

Drs. Benjamin Lins de Albuquerque, Manoel B. Vieira Cavalcanti Filho, Affonso Alves de Camargo, Manoel Barreto Vieira de Alencar e Claudino R. Ferreira dos Santos ( do Curso de Direito); Drs. João Moreira Garcez, Adriano Goulin, Manoel Lustosa Carrão, João David Pernetta, Plinio Monteiro Tourinho, Candido Ferreira de Abreu e José Niepce da Silva ( do Curso de Engenharia); Drs. João Evangelista Espindola, Abdon Petit Carneiro, Arthur Obino e Antonio Virgolino Brazil ( dos Cursos de Obstetrícia e Odontologia); Drs. Sebastião Paraná, Arthur Loyola e Generoso Borges ( do Curso de Comércio).

Na ocasião, por proposta de Nilo Cairo, o Presidente do Estado seria nomeado Diretor Honorário da Universidade do Paraná. No mesmo local, às 19 horas, o presidente do Estado abre a sessão de instalação da Universidade do Paraná na presença de todos os Secretários de Estado, autoridades civis e militares. 
Em fevereiro de 1913, Flavio Luz deixaria a Tesouraria devido a sua exigüidade de tempo, sendo substituído pelo Contador João Soares Barcellos, lente substituto do curso de Comércio.

Os recursos financeiros iniciais seriam fornecidos pelos emolumentos pagos pelos lentes na assinatura de posse no valor de $30 \$ 000$ (trinta mil réis), tendo os membros da Diretoria e do Conselho Econômico, contribuído cada um com $20 \$ 000$ (vinte mil réis).

Com estes recursos abriu-se conta no London and Brazilian Bank, solicitando-se crédito de até dez contos de réis para adquirir os primeiros móveis e utensílios, o crédito não seria utilizado.

Dois dias após o ato inaugural, Victor do Amaral é encarregado de alugar o prédio $\mathrm{n}^{\mathbf{0}} 42$ da Rua Comendador Araújo para abrigar as atividades iniciais da Universidade. Atualmente o local abriga um shopping, onde se pode ver placa de bronze comemorativa ali afixada quando das comemorações dos 75 anos de fundação da instituição.

Elabora-se o emblema da Universidade, que desenhado pelo Coronel Paulo de Assumpção, consistia em um símbolo representando o mundo iluminado pela ciência, ladeado por dois ramos, um de carvalho representando o poder da vontade, outro de louro, representando o poder da inteligência, com o lema scientia et labor, ciência e trabalho. É o símbolo que permanece até os dias atuais. Abaixo o simbolo original do primeiro relatório, em 1913, da Universidade do Paraná.

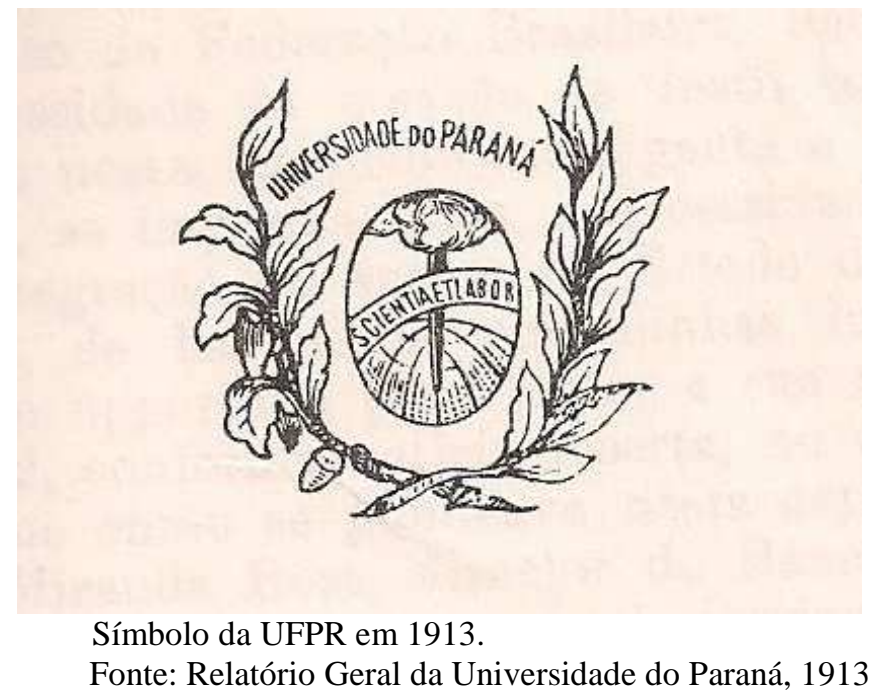


Em fevereiro de 1913, são executados os exames de admissão, sendo matriculados no Curso de Engenharia 32 alunos; no de Ciências Jurídicas e Sociais 29; no de Odontologia 13; no de Farmácia 10; no de Comércio 13. Para o curso de Obstetrícia não houve inscrição. As aulas se iniciam em março com 97 alunos. As mensalidades pagas pelos alunos variavam de 40\$000 (quarenta mil réis) a 30\$000(trinta mil réis) a depender do curso.

Os alunos se organizam, em abril, fundam o Centro Universitário. Em finais de outubro, partem os estudantes em passeata, ao som de banda marcial, sob a liderança do estudante de Engenharia Lysimaco Ferreira da Costa, rumo ao Palácio do Governo, no alto de São Francisco onde hoje se situa o Museu Paranaense -, após manifestações, seguem para a Diretoria da Universidade, não era um movimento de protesto, era de agradecimento. Agradecimento, dando vivas ao nosso deputado federal Luiz Bartolomeu de Souza e Silva e ao presidente do Estado Carlos Cavalcanti, cujos esforços viabilizaram a subvenção anual de cinqüenta contos de réis ao Curso de Engenharia, aprovado pelo Congresso Nacional e sancionada pelo Presidente Marechal Hermes da Fonseca, em 23 de outubro de 1913. O deputado receberia, mais tarde, o Diploma de Benfeitor da Universidade do Paraná.

Anteriormente, o projeto de lei do deputado João David Pernetta, lente do curso de Engenharia, o mesmo que incentivou a sua criação, seria aprovado, originando a Lei Estadual 1.284 de 27 de março de 1913, reconhecendo oficialmente a Universidade do Paraná e autorizando o Executivo a concorrer para o seu patrimônio. O que é realizado com a subvenção de 80:000\$000 (Oitenta contos de réis), divididos em duas parcelas.

Os recursos viabilizariam a compra de terreno na esquina das ruas Carlos de Carvalho e Visconde de Nacar, medindo 68 metros por 66metros, para iniciar-se a construção do prédio da instituição de ensino superior. O terreno seria permutado com a Prefeitura de Curitiba pela área onde hoje se encontra o prédio histórico da Universidade, na Praça Santos Andrade. No local, em 31 de agosto de 1913, é lançada a pedra fundamental do edifício da Universidade do Paraná.

A permuta seria transformada, pouco tempo após, em doação, por decisão da Câmara de Vereadores e do prefeito Dr. Candido Ferreira de Abreu, que era membro do Conselho Superior da Universidade e lente do curso de Engenharia. A doação aumentou o patrimônio da Universidade, abrindo-se a alternativa de transformar a área em lotes, cuja venda poderia garantir mais recursos para investimentos. 
O projeto do edifício é proposto pelo Engenheiro Baeta de Faria, que era lente do curso de Engenharia, e complementado pelos Engenheiros Militares Euclides Espindola e Arthur Portella.

A trajetória da Universidade do Paraná, que viria a ser federalizada no ano 50 do século passado, passando a denominar-se Universidade Federal do Paraná, é assim iniciada, legando um exemplo de coesão comunitária na busca de um nobre objetivo. Neste século de existência sua história se confunde com a história de nosso Estado. Não apenas formou quadros técnicos e lideranças políticas, mas sempre esteve envolvida na contribuição de soluções técnicas e científicas dos problemas e indagações que buscavam o desenvolvimento social e econômico do Estado do Paraná.

Como profetizava o engenheiro Dr. Arthur Martins Franco, em discurso, em julho de 1913, quando da posse do lente Dr. Luiz Caetano de Oliveira, na cadeira de Mineralogia e Geologia, do curso de Engenharia, que assim, em parte, se expressava, referindo-se a Universidade:

Tornada, assim, a cellula mater de todas as atividades que se hão de traduzir, no nosso meio, no comerciante, no medico, no advogado, no engenheiro, dando ensanchas, uns à nossa expansão econômica, abrindo novos mercados às nossas riquezas e as nossas indústrias; criando hospitais [.....]; interpretando, aqueles, as nossas leis, concorrendo para codificá-las n'um corpo único de doutrina, retirando a evasiva bigumea, cristalizando-as nos textos claros e incisivos, [....]; rasgando, estes, estradas pelas encostas,contornando colinas, descendo vales, galgando planaltos, transpondo caudais, acompanhando rios,vencendo campinas; rasgando as florestas até os penetrais dos nossos sertões; armazenando a hulha branca das catadupas para transformá-las em força, calor e luz; abrindo o seio da terra, explorando as ricas jazidas, para não se ouvir por toda a parte senão o rumor das rodas, o silvar das locomotivas, o som do malho repercutindo a incude aliado ao canto alegre do lavrador, do operário e da juventude, sobraçando esta o livro, guiando aquele o arado, tudo isso reunido n'um único e eterno hino ao trabalho - a Universidade do Paraná terá colaborado assim na obra grandiosa deste abençoado torrão. [...].(A REPUBLICA, 1913, 29/07).

A primeira Diretoria da Universidade do Paraná, imortalizada em quadro² (abaixo), pintado, em ato simbólico, quando das comemorações dos 75 anos da instituição, pelo ex-aluno, Professor Emérito da Universidade Federal do Paraná, Ex-Ministro da Educação, na ocasião, Reitor da Pontifícia Universidade Católica do Paraná, Engenheiro Dr. Euro Brandão, se encontra na sala do Egrégio Conselho Universitário a contemplar as decisões do órgão máximo da Universidade

\footnotetext{
${ }^{2}$ Foto em escala de Ana Assunção, Assessoria de Comunicação Social - UFPR.
} 
tendo a convicção da superação das dificuldades que envolvem a centenária instituição e da continuidade das proféticas palavras de Arthur Martins Franco.

Pela ordem: Hugo Gutierrez Simas (Bibliotecario), João Soares Barcellos (Tesoureiro), Manoel de Cerqueira Daltro Filho (Sub-secretário), Nilo Cairo da Silva (Secretário), Euclides Bevilaqua (Vice-diretor) e Victor Ferreira do Amaral e Silva (Diretor)

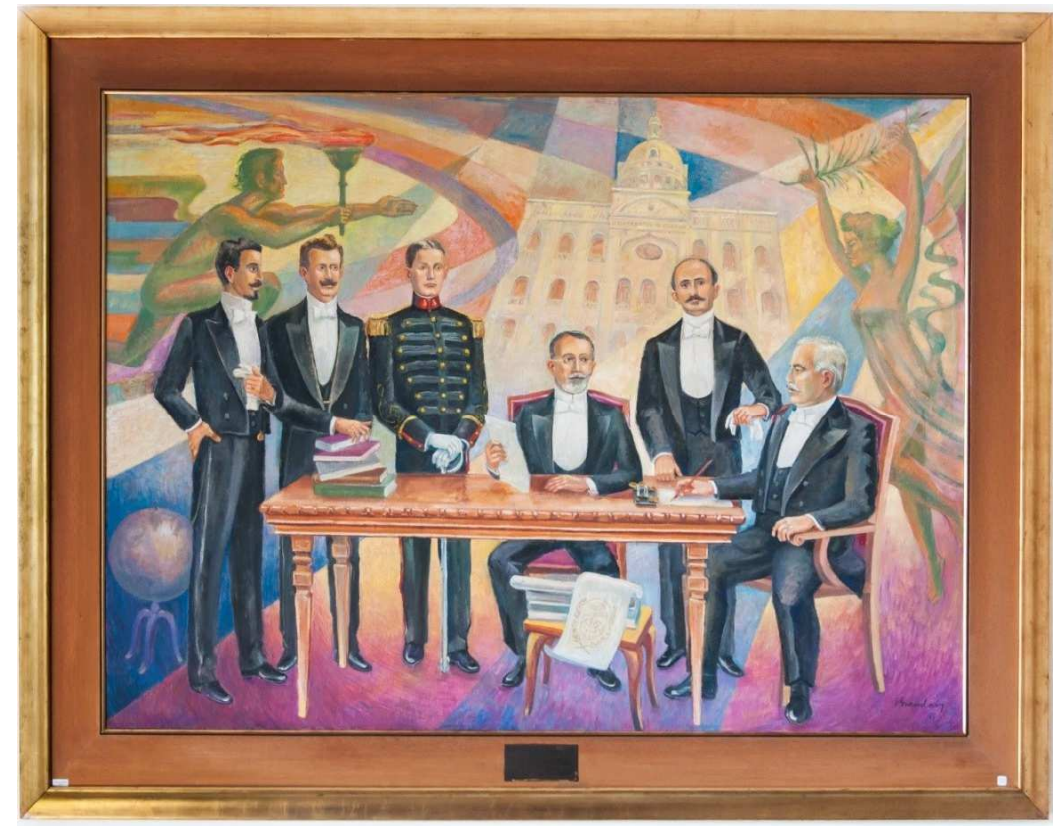

Pela ordem: Hugo Gutierrez Simas (Bibliotecario), João Soares Barcellos (Tesoureiro), Manoel de Cerqueira, Daltro Filho (Sub-secretário), Nilo Cairo da Silva (Secretário), Euclides Bevilaqua (Vice-diretor) e Victor Ferreira do Amaral e Silva (Diretor)

\section{REFERÊNCIAS}

RELATÓRIO GERAL DA UNIVERSIDADE DO PARANÁ DE 1913, Curitiba: Typ. Alfredo Hoffmann, 1913. Reeditado pela UFPR em 1987, acervo do autor.

Jornal "A Republica”, 1892, 15 de dezembro, Curytiba, acervo da Fundação Biblioteca Nacional, disponível em memoria.bn.br. 1893, 23 de abril. 
1894, 25 de maio 1894, 10 de julho. 1894, 11 de julho 1894, 17 de julho. 1894, 25 de julho. 1896, 31 de outubro. 1898, 20 de setembro. 1911, 07 de abril. 1912, 11 de agosto. 1912, 21 de dezembro. 1912, 23 de dezembro. . 1912, 24 de dezembro. . 1913, 10 de abril. . 1913, 29 de abril. 1913, 29 de julho. 1913, 19 de setembro. 1913, 17 de outubro. 1913, 18 de novembro. 1913, 24 de outubro. 1913, 27 de outubro. 1913, 29 de outubro. . 1913, 30 de outubro. . 1913, 08 de dezembro. . 1915, 07 de outubro. . 1915, 28 de outubro. .1915, 01 de novembro. 